\title{
Measurements of oxygen saturation of brain, liver and heart areas in the supine and sitting position using near infrared spectrophotometry
}

\author{
Athanasia Tsaroucha, Anteia Paraskeva, Argyro Fassoulaki
}

National and Kapodistrian University of Athens, Aretaieio Hospital, Department of Anesthesiology, Athens, Greece

\begin{abstract}
Background and aims: Regional oxygen saturation $\left(\mathrm{rSO}_{2}\right)$ monitoring of the brain by near-infrared spectroscopy (NIRS) has been mainly used during carotid endarterectomy. The present study was conducted in volunteers and investigates the $\mathrm{rSO}_{2}$ values of the brain, heart and liver tissue as assessed by NIRS in the supine and the sitting position.

Methods: After obtaining written informed consent from forty-nine healthy volunteers, $\mathrm{rSO}_{2}$ values were recorded in the heart and liver areas in the supine and the sitting position, while simultaneously the $\mathrm{rSO}_{2}$ values of the brain.

Results: The $\mathrm{rSO}_{2}$ brain values in the supine and the sitting position were $69 \pm 6.0$ and $66 \pm 6.1$ respectively $(\mathrm{p}=0.0001)$. The $\mathrm{rSO}_{2}$ values in the supine and the sitting position were $76 \pm 10.5$ and $79 \pm 6.7$ for the heart $(\mathrm{p}>0.05)$ and $85 \pm 6.8$ and $82 \pm 7.2$ for the liver, $(\mathrm{p}=0.007)$. Heart $\mathrm{rSO}_{2}$ values were higher than the brain $\mathrm{rSO}_{2}$ values in both the supine $(76 \pm 10.4$ versus $69 \pm 6.6 ; \mathrm{p}=0.0001)$ and the sitting position (79 \pm 6.7 versus $66 \pm 6.1 ; \mathrm{p}=0.0001$ ). The liver $\mathrm{rSO}_{2}$ values were also higher than the brain $\mathrm{rSO}_{2}$ values in the supine ( $85 \pm 6.8$ versus $69 \pm 6.0 ; \mathrm{p}=0.0001)$ and in the sitting position $(82 \pm 7.2$ versus $66 \pm 5.7 ; \mathrm{p}$ $=0.0001)$. Arterial blood pressure and arterial oxygen saturation $\left(\mathrm{SpO}_{2}\right)$ did not differ between the two positions but the heart rate was higher in the sitting position $(\mathrm{p}=0.030)$.

Conclusions: We conclude that brain and liver (but not heart) $\mathrm{rSO}_{2}$ values are higher in the supine than sitting position. Additionally, NIRS may be used to assess oxygenation of the heart and liver.

Keywords: tissue oxygenation, near infrared spectroscopy (NIRS), brain oxygenation, heart oxygenation, liver oxygenation

\section{Introduction}

Cerebral oximetry by near-infrared spectroscopy (NIRS) measures intracerebral oxygen saturation $\left(\mathrm{rSO}_{2}\right)$ continuously and non-invasively [1]. The method has been validated and used extensively during carotid endarterectomy to monitor the $\mathrm{rSO}_{2}$ values during carotid clamping [2, 3]. It has also been used in stroke and cardiac arrest patients to detect desaturation of

Address for correspondence:

Athanasia Tsaroucha, MD, PhD

76 Vassilissis Sofias Ave

11528 Athens, Greece

E-mail: ntsaroucha@yahoo.com

the metabolically active brain but may exhibit normal values in the absence of cerebral perfusion [4]. Cerebral oximetry is useful during coronary artery bypass surgery as its use is associated with a shorter length of stay in the ICU, lower incidence of stroke, renal failure, deep sternal infection, prolonged ventilation, reoperation and death [5].

In elderly patients undergoing major abdominal surgery, monitoring of cerebral oxygen saturation revealed that cerebral desaturation is common, and it is associated with early postoperative cognitive dysfunction that can be corrected by blood transfusion $[6,7]$. The $\mathrm{rSO}_{2}$ values depend on blood flow and on the perfusion pressures and oxygen extraction by the different tissues. Our hypothesis was that regional
\end{abstract}


hemoglobin saturation is posture dependent, thus $\mathrm{rSO}_{2}$ values will change from supine to sitting position and vice versa. We also hypothesized that cerebral oximetry may be used to assess the oxygenation of other vital organs like heart and liver.

The aim of this prospective observational study was to evaluate changes in the $\mathrm{rSO}_{2}$ in volunteers due to changes in position (from sitting to supine or the other way around) using the INVOS 4100 cerebral oximeter (Somanetics, Troy, MI, USA). A secondary aim was to investigate the potential of monitoring the regional oxygenations of other organs such as the liver and heart by means of NIRS in both the supine and sitting positions.

\section{Methods}

After obtaining approval from the Institutional Review Board (IRB), 36 women and 13 men gave written informed consent to participate in the study. All volunteers were ASA I physical status with a mean age of 30 (min-max: 20-61) years. Exclusion criteria included intake of drugs with effect on the nervous system (such as benzodiazepines and opioids), obesity, smoking and alcoholism. The study was performed between June 2006 and November 2009.

Measurements included simultaneous $\mathrm{rSO}_{2}$ recordings of the brain and heart in the supine and sitting positions. Similarly, $\mathrm{rSO}_{2}$ recordings of the liver in both supine and sitting position were performed simultaneously with $\mathrm{rSO}_{2}$ recordings of the brain, as NIRS is primarily the method used to measure the regional hemoglobin saturation in the brain. All measurements for heart and liver along with the brain measurements as a standard comparator were performed on the same day. The $\mathrm{rSO}_{2}$ of each organ was measured with the INVOS 4100 cerebral oximeter (Somanetics, Troy, MI, USA) and the Somanetics disposable sensor.

Systolic and diastolic arterial pressure as well as arterial oxygen saturation by means of pulse oximeter $\left(\mathrm{SpO}_{2}\right)$ was also measured along with the $\mathrm{rSO}_{2}$ measurements. The order of the position for measurements, supine versus sitting, was determined by a coin toss. Regarding liver versus heart $\mathrm{rSO}_{2}$ measurements, the order was determined with opaque sealed envelopes containing the code for the relevant tissue. Systolic and diastolic arterial blood pressure, heart rate and $\mathrm{SpO}_{2}$ were recorded before and after $\mathrm{rSO}_{2}$ measurements in each position.

The left disposable INVOS sensor was applied on the ipsilateral temporal area of the brain, specifically on the left forehead with the caudal border about $1 \mathrm{~cm}$ above the eyebrow and the medial edge on the midline, between the two eyebrows. The right sensor was attached over the sternum area, or over the liver area according to the order of randomization (Fig. 1). The volunteer was allowed to relax in the predetermined position at least 5 minutes and subsequently remained in this position to accomplish the series of measurements, thus $\mathrm{rSO}_{2}$ values of the brain and the predetermined organ. Subsequently the right sensor was applied over the next tissue while the left sensor remained on the temporal area. The $\mathrm{rSO}_{2}$ values of the brain and the next tissue, liver or heart were recorded. When measurements were completed at the supine or the sitting position the volunteer was asked to change position and to remain relaxed for more than 5 minutes. Then the whole series of measurements was repeated in the new position.

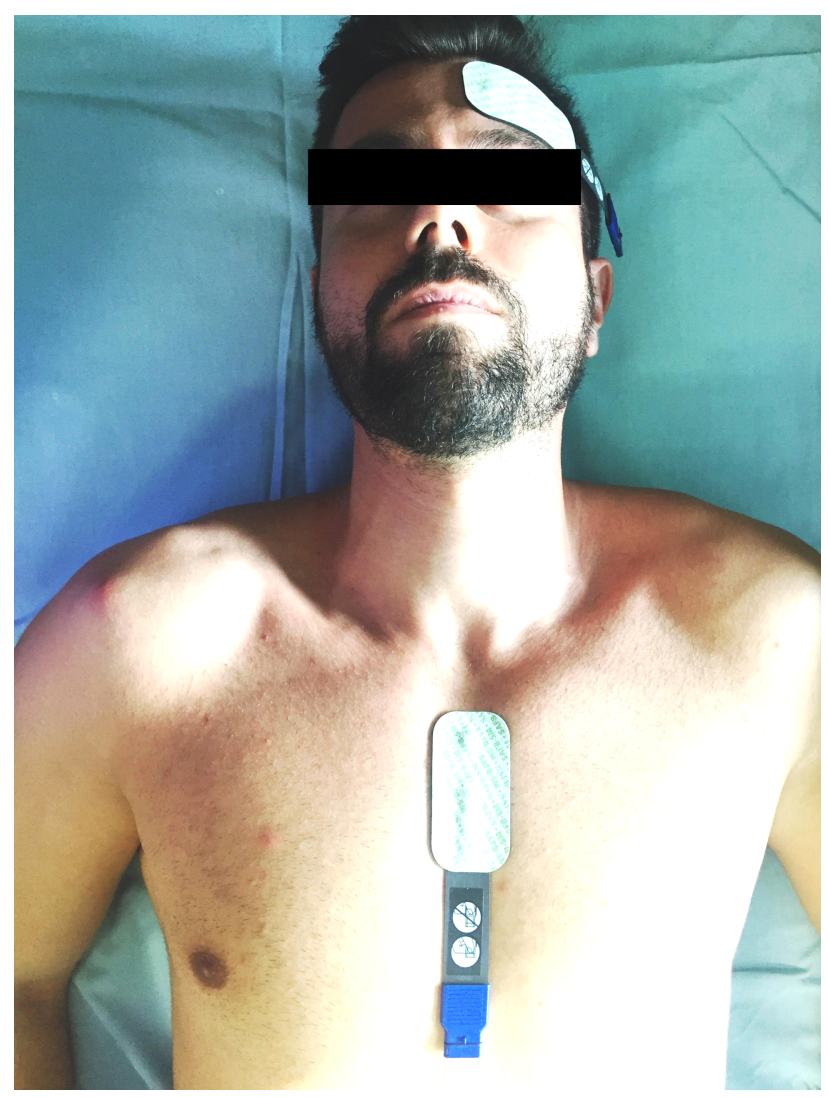

Fig. 1. Sensor placement over the brain and heart areas

The primary endpoint of the study was determination of the $\mathrm{rSO}_{2}$ values in each organ in the supine versus the sitting position. The secondary end point was to compare the $\mathrm{rSO}_{2}$ values obtained from the sensor applied on the sternum area representing theheart and the right sub costal area representing the liver with the values recorded simultaneously from the brain.

A priori power analysis (GPower 3.0.8, Universität Düsseldorf, Germany) showed that in order to find a medium size $(0.25)$ of effect according to d Cohen's 
coefficient, between the brain $\mathrm{rSO}_{2}$ in the supine and sitting positions, which corresponds to $6 \%$ variance, with a power of 0.90 and an error $a=0.5$, a sample of 45 subjects was needed.

Statistical analysis was performed with SPSS, IBM statistical package (version 17.0). According to Kolmogorov Smirnov test all $\mathrm{rSO}_{2}$ values followed normal distribution.

The heart rate and the $\mathrm{rSO}_{2}$ values in the supine versus the sitting position obtained from each individual organ were analyzed with paired t-test. Similarly, paired t-test was used to compare the $\mathrm{rSO}_{2}$ values between the brain and the heart and between the brain and the liver in both supine and sitting position. Systolic and diastolic arterial pressure and arterial oxygen saturation $\left(\mathrm{SpO}_{2}\right)$ values in the supine versus the sitting position did not follow normal distribution and were analyzed with Wilcoxon Signed Ranks test. A value of $p<0.05$ was considered statistically significant.

\section{Results}

Measurements were performed in all volunteers and their characteristics are shown in Table 1. Incomplete measurements were one $\mathrm{rSO}_{2}$ value in the heart recordings with the volunteer in the supine position, and six and four $\mathrm{rSO}_{2}$ values during measurements with the sensor over the liver at the supine and sitting position, respectively. These values were not obtained due to technical reasons.

Table 1. Age, body weight and height in the 49 volunteers recruited for the study

\begin{tabular}{ll}
\hline Age (years) & $30(20-61)$ \\
Body Weight $(\mathrm{kg})$ & $65(47-100)$ \\
Height $(\mathrm{cm})$ & $169(150-180)$ \\
\hline
\end{tabular}

Values are mean (range)

The $\mathrm{rSO}_{2}$ comparisons for the same organ between the supine and the sitting position are shown in table 2 and figure 2. The $\mathrm{rSO}_{2}$ values obtained for the brain and the liver were lower in the sitting when compared to the supine position $(\mathrm{p}=0.0001$ and $\mathrm{p}=0.007$, respectively). However, we found no significant differences in the $\mathrm{rSO}_{2}$ values between the supine and sitting position in the heart $(p=0.212)$.

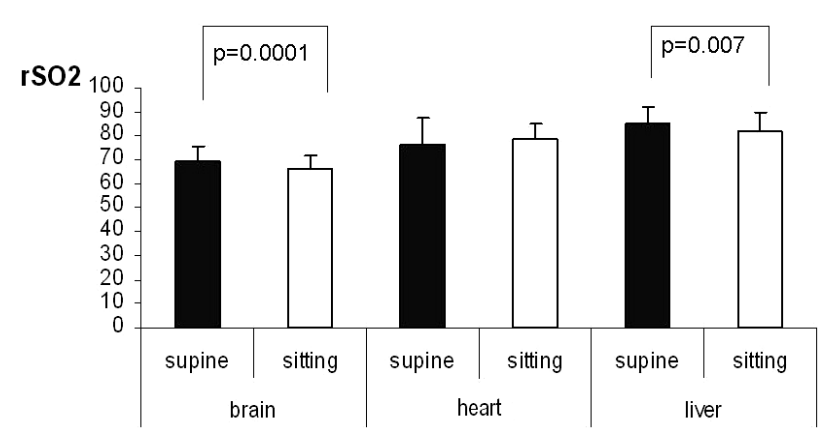

Fig. 2. The $\mathrm{rSO}_{2}$ values of the brain, heart and liver in the supine versus the sitting position

The $\mathrm{rSO}_{2}$ comparisons between brain and heart and brain and liver in the supine and the sitting position are shown in table 3 and figure 3 . The heart area exhibited higher $\mathrm{rSO}_{2}$ values when compared to the brain in both the supine and the sitting position $(\mathrm{p}=0.0001$ and $\mathrm{p}=$ 0.0001 , respectively). This might be due to the venous blood return to the heart, which is increased in the supine position, while in the same position the brain receives more arterial blood. With regard to the brain

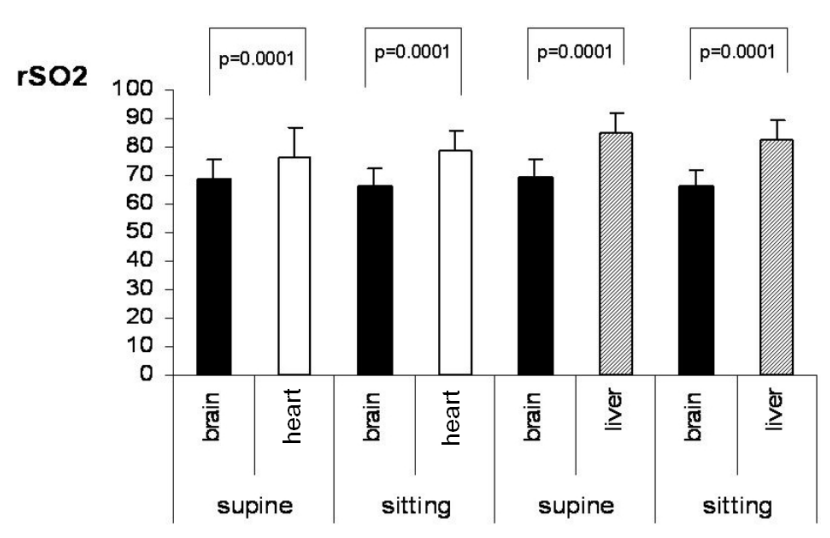

Fig. 3. The $\mathrm{rSO}_{2}$ values of the brain versus heart and of the brain versus liver in the sitting and in the supine position

Table 2. The $\mathrm{rSO}_{2}$ values in the supine and sitting position for the brain, heart and liver tissue

\begin{tabular}{lllllc}
\hline \multicolumn{2}{c}{ Brain } & \multicolumn{2}{c}{ Heart } & \multicolumn{2}{c}{ Liver } \\
\hline Supine & Sitting & Supine & \multicolumn{1}{c}{ Sitting } & Supine & \multicolumn{1}{c}{ Sitting } \\
$(\mathrm{N}=49)$ & $(\mathrm{N}=49)$ & $(\mathrm{N}=48)$ & $(\mathrm{N}=49)$ & $(\mathrm{N}=43)$ & $(\mathrm{N}=45)$ \\
$69 \pm 6.0$ & $66 \pm 5.7$ & $76 \pm 10.5$ & $79 \pm 6.7$ & $85 \pm 6.8$ & $82 \pm 7.2$ \\
$67.7-71.1$ & $64.6-67.9$ & $73.5-79.6$ & $76.7-80.6$ & $82.9-87.1$ & $80.1-84.4$ \\
\multicolumn{1}{c}{$\mathrm{t}=-5.837, \mathrm{p}=0.0001$} & \multicolumn{2}{c}{$\mathrm{t}=1.26, \mathrm{p}=0.212$} & \multicolumn{2}{c}{$\mathrm{t}=-2825, \mathrm{p}=0.007$} \\
\hline
\end{tabular}

Values are mean $\pm \mathrm{SD}, 95 \%$ confidence interval and $\mathrm{t}$ score 
Table 3. The $\mathrm{rSO}_{2}$ values of the brain compared to the $\mathrm{rSO}_{2}$ values obtained from heart and to the $\mathrm{rSO}_{2}$ values obtained from the liver in the supine and sitting position

\begin{tabular}{llllllll}
\hline \multicolumn{2}{r}{ Supine } & \multicolumn{2}{c}{ Sitting } & \multicolumn{2}{c}{ Supine } & \multicolumn{2}{c}{ Sitting } \\
\hline Brain & Heart & Brain & Heart & Brain & Liver & Brain & Liver \\
$(\mathrm{N}=49)$ & $(\mathrm{N}=48)$ & $(\mathrm{N}=49)$ & $(\mathrm{N}=49)$ & $(\mathrm{N}=49)$ & $(\mathrm{N}=43)$ & $(\mathrm{N}=49)$ & $(\mathrm{N}=45)$ \\
$69 \pm 6.6$ & $76 \pm 10.4$ & $66 \pm 6.1$ & $79 \pm 6.7$ & $69 \pm 6.0$ & $85 \pm 6.8$ & $66 \pm 5.7$ & $82 \pm 7.2$ \\
$67.1-70.9$ & $73.5-79.6$ & $64.3-67.8$ & $76.7-80.6$ & $67.7-71.1$ & $82.9-87.1$ & $64-67.9$ & $80-84.4$ \\
\multicolumn{2}{c}{$\mathrm{t}=-5.079, \mathrm{p}=0.0001$} & \multicolumn{2}{c}{$\mathrm{t}=-10.114, \mathrm{p}=0.0001$} & \multicolumn{2}{c}{$\mathrm{t}=-10.542, \mathrm{p}=0.0001$} & & $\mathrm{t}=-11.576, \mathrm{p}=0.0001$ \\
\hline
\end{tabular}

Values are mean $\pm \mathrm{SD}$ and $95 \%$ confidence interval

and liver comparisons, the liver $\mathrm{rSO}_{2}$ values are higher in both the supine $(\mathrm{p}=0.0001)$ and sitting position $(\mathrm{p}=$ 0.0001 ). The $\mathrm{rSO}_{2}$ difference between brain and liver in both positions is the same $(16 \%)$ considering that both organs receive more arterial blood in the supine position.

We found no difference in the $\mathrm{SpO}_{2}$ values recorded during the $\mathrm{rSO}_{2}$ measurements of the heart and the liver between the supine and the sitting position $(\mathrm{p}=$ 0.738 and $p=0.434$ respectively). Similarly systolic and diastolic blood pressures did not differ significantly $(p=0.311$ and $p=0.73$ respectively). Heart rate was higher in the sitting versus the supine position $(\mathrm{p}=$ 0.030 ).

\section{Discussion}

The results of the present study demonstrate that $\mathrm{rSO}_{2}$ values for the brain and for other areas of the body measured by NIRS vary with the patient's posture. The data also showed that $\mathrm{rSO}_{2}$ measured in the brain and heart area in the sitting position differ. The $\mathrm{rSO}_{2}$ values between brain and liver differ and this difference is the same in both positions $(16 \%)$.

Several factors may interfere and influence the $\mathrm{rSO}_{2}$ measurements by NIRS. Kishi et al. investigated the $\mathrm{rSO}_{2}$ values in the brain obtained after a sensor position at different sites on the forehead and also the impact of factors such as patient characteristics and hemoglobin concentration [8]. The sensor location, age and hemoglobin all are determinants of the $\mathrm{rSO}_{2}$ values. An inverse relationship was found between age and $\mathrm{rSO}_{2}$ values and a direct relationship between hemoglobin and $\mathrm{rSO}_{2}$ values [8]. In fact in elderly patients undergoing prolonged major abdominal surgery the significant decreases observed in $\mathrm{rSO}_{2}$ during major hemorrhage, despite maintenance of blood pressure responded only to blood transfusion [7]. We did not include elderly volunteers so we do not expect age to have an impact to the $\mathrm{rSO}_{2}$ values we measured. We did not measure the hemoglobin of our volunteers with free history for disease as our interest was focused on possible changes in the $\mathrm{rSO}_{2}$ with changes in posture and not on absolute $\mathrm{rSO}_{2}$ values.
Yoshitani et al. evaluated clinically the skull thickness, the area of the cerebrospinal fluid layer, the mean arterial pressure and the hemoglobin concentration, and found that all are determinants of the NIRS values [9]. These parameters had no effect on the tissue oxygen index, which is the ratio of oxyhemoglobin to total hemoglobin.

Nonetheless, these factors are dependent upon the technique of measurement and not upon the patient's factors as in the $\mathrm{rSO}_{2}$ measurements the calculations include the optical path length, while in the tissue oxygen index algorithm the optical path length is not included in the formula [10]. For this reason the same parameters had no effect on the tissue oxygen index.

In our study the impact of the different factors that may influence the $\mathrm{rSO}_{2}$ measurements, such as hemoglobin and patients' characteristics are constant and do not change during the measurements obtained in the different positions or in the different body areas. Therefore, these variables are not expected to affect the measurements in different ways.

The $\mathrm{rSO}_{2}$ was found to increase significantly when NIRS assessments were made with the subjects placed from the supine to the $20^{\circ}$ Trendelenburg position, but not in the $20^{\circ}$ reverse Trendelenburg position [11]. Similarly, in our study the supine position is associated with increased $\mathrm{rSO}_{2}$ values in both the brain and liver compared to the sitting position. This change, which may not be clinically significant, is likely related to increased cardiac output due to increased venous return in the supine position. In contrast, in the heart we found higher $\mathrm{rSO}_{2}$ values in the sitting position. This could be explained by the fact that in the supine position the increased return of venous blood goes directly to the heart decreasing so the $\mathrm{rSO}_{2}$ value. The finding that $\mathrm{rSO}_{2}$ values in the heart are higher in the sitting than in the supine position suggests that the sternum area may be appropriate location for the sensor to monitor the heart $\mathrm{rSO}_{2}$. Additionally other locations for placement of the sensor to monitor the $\mathrm{rSO}_{2}$ of the heart (such as the apical area of the chest) are not always feasible particularly in women due to the breasts. 
Arterial blood pressure and $\mathrm{SpO}_{2}$ may also influence the NIRS measurements. Yoshitani et al. found that mean arterial pressure was a significant factor that determines the $\mathrm{SpO}_{2}$ [9]. In a retrospective study Paquet et al. reported that $\mathrm{rSO}_{2}$ brain values correlated significantly to the central venous pressure, the pulmonary capillary wedge pressure, the mean pulmonary artery pressure, the mean arterial pressure/mean pulmonary artery pressure ratio, the left fractional area change and the regional and motion score index and the diastolic function [12]. The authors conclude that NIRS may have a place in cardiac function assessment.

Although we found changes in the $\mathrm{rSO}_{2}$ between the supine and the sitting position systolic and diastolic arterial pressure did not change. This finding may be explained by the fact that the volunteers were young subjects and compensated by the increase in heart rate. Sitting position is rarely used today during surgery, aside from neurological (sitting craniotomy) and orthopedic (shoulder surgery) procedures. However the changes in the $\mathrm{rSO}_{2}$ values we observed imply possible changes of this variable when positions other than the supine are adopted intraoperatively.

Regarding the $\mathrm{rSO}_{2}$ in areas other than the brain, to our knowledge no previous studies used INVOS to investigate the feasibility of monitoring the $\mathrm{rSO}_{2}$ in other organs such as heart or liver. The $\mathrm{rSO}_{2}$ values we recorded in the sternum area are consistent with those close to the $\mathrm{SvO}_{2}$ values in healthy subjects. Considering the $\mathrm{rSO}_{2}$ of the brain as the gold standard we found higher $\mathrm{rSO}_{2}$ values primarily in the liver and secondarily in the heart areas. Nonetheless, each tissue exhibits its own $\mathrm{rSO}_{2}$ values and the importance may be the changes in $\mathrm{rSO}_{2}$, particularly in critical situations like multiple organ failure.

The consistent difference between the $\mathrm{rSO}_{2}$ values in the brain and liver in both positions suggests that the method and the medical device may be useful to monitor oxygenation of the liver but the $\mathrm{rSO}_{2}$ baseline values should be higher. Also the fact that the $\mathrm{rSO}_{2}$ values obtained in the heart do not differ between the two positions, evidently due to the increased return of venous blood to the heart in the supine position suggests that the method may be useful to monitor the global oxygenation of the heart.

\section{Conclusion}

The position of the patient influences the $\mathrm{rSO}_{2}$ values measured by NIRS in the brain and liver but not in the heart. However, our results are limited to healthy young subjects not undergoing surgery. More studies are required to validate and expand these data to patients undergoing major surgery as well as to older, sicker surgical patients. The method and the apparatus may be useful to monitor the global oxygenation of the heart and the liver as well.

\section{Conflict of interest}

Nothing to declare

\section{Funding statement}

This work has been done without any financial support or sponsorship.

\section{References}

1. Jöbsis FF. Noninvasive, infrared monitoring of cerebral and myocardial oxygen sufficiency and circulatory parameters. Science 1977; 198: 1264-1267. doi: 10.1126/science.929199

2. Moritz S, Kasprzak P, Arlt M, Taeger K, Metz C. Accuracy of cerebral monitoring in detecting cerebral ischemia during carotid endarterectomy: a comparison of transcranial Doppler sonography, near-infrared spectroscopy, stump pressure, and somatosensory evoked potentials. Anesthesiology 2007; 107 : 563-569. doi: 10.1097/01.anes.0000281894.69422.ff

3. Samra SK, Dy EA, Welch K, Dorje P, Zelenock GB, Stanley JC. Evaluation of a cerebral oximeter as a monitor of cerebral ischemia during carotid endarterectomy. Anesthesiology 2000; 93: 964-970

4. Nemoto EM, Yonas H, Kassam A. Clinical experience with cerebral oximetry in stroke and cardiac arrest. Crit Care Med 2000; 28: 1052-1054. doi: 10.1097/00003246-20000400000023

5. Murkin JM, Adams SJ, Novick RJ, Quantz M, Bainbridge D, Iglesias I, et al. Monitoring brain oxygen saturation during coronary bypass surgery: a randomized, prospective study. Anesth Analg 2007; 104: 51-58. doi: 10.1213/01.ane.0000246814. 29362.f4

6. Casati A, Fanelli G, Pietropaoli P, Proietti R, Tufano R, Montanini $\mathrm{S}$, et al. Monitoring cerebral oxygen saturation in elderly patients undergoing general abdominal surgery: a prospective cohort study. Eur J Anaesthesiol 2007; 24: 59-65. doi: $10.1017 / \mathrm{S} 0265021506001025$

7. Green DW. A retrospective study of changes in cerebral oxygenation using a cerebral oximeter in older patients undergoing prolonged major abdominal surgery. Eur J Anaesthesiol 2007; 24: 230-234. doi: 10.1017/ S0265021506001645

8. Kishi K, Kawaguchi M, Yoshitani K, Nagahata T, Furuya H. Influence of patient variables and sensor location on regional cerebral oxygen saturation measured by INVOS 4100 nearinfrared spectrophotometers. J Neurosurg Anesthesiol 2003; 15: 302-306

9. Yoshitani K, Kawaguchi M, Miura N, Okuno T, Kanoda T, Ohnishi Y, et al. Effects of hemoglobin concentration, skull thickness, and the area of the cerebrospinal fluid layer on nearinfrared spectroscopy measurements. Anesthesiology 2007; 106: 458-462

10. Okada E, Delpy DT. Near-infrared light propagation in an adult head model. II. Effect of superficial tissue thickness on the sensitivity of the near-infrared spectroscopy signal. Appl Opt 2003; 42: 2915-2922. doi: 10.1364/AO.42.002915 
11. Pollard V, Prough DS, DeMelo E, Deyo DJ, Uchida T, Widman $\mathrm{R}$. The influence of carbon dioxide and body position on nearinfrared spectroscopic assessment of cerebral hemoglobin oxygen saturation. Anesth Analg 1996; 82: 278-287. doi: 10.1097/00000539-199602000-00011
12. Paquet C, Deschamps A, Denault AY, Couture P, Carrier M, Babin D, et al. Baseline regional cerebral oxygen saturation correlates with left ventricular systolic and diastolic function. J Cardiothorac Vasc Anesth 2008; 22: 840-846. doi: 10.1053/ j.jvca.2008.02.013 